\title{
The personal self of psychotherapists : Dimensions, correlates, and relations with clients
}

\section{Orlinsky, David E.}

2020-03

Orlinsky, D E , Ronnestad, M H , Hartmann , A, Heinonen, E \& Willutzki , U 2020 , ' The personal self of psychotherapists : Dimensions, correlates, and relations with clients ' , Journal of Clinical Psychology, vol. 76 , no. 3 , pp. 461-475 . https://doi.org/10.1002/jclp.22876

http://hdl.handle.net/10138/321394

https://doi.org/10.1002/jclp.22876

acceptedVersion

Downloaded from Helda, University of Helsinki institutional repository.

This is an electronic reprint of the original article.

This reprint may differ from the original in pagination and typographic detail.

Please cite the original version. 
The Personal Self of Psychotherapists: Dimensions, Correlates and Relations with Clients

David E. Orlinsky ${ }^{\mathrm{a}}$, Michael Helge Rønnestad ${ }^{\mathrm{b}}$, Armin Hartmann $^{\mathrm{c}}$, Erkki Heinonen ${ }^{\mathrm{d}}$ \& Ulrike Willutzki

${ }^{\mathrm{a}}$ University of Chicago (USA), ${ }^{\mathrm{b}}$ University of Oslo (Norway), ${ }^{\mathrm{c}}$ University of Freiburg

(Germany), ${ }^{\mathrm{d}}$ University of Helsinki (Finnland), ${ }^{\mathrm{e}}$ University of Witten/Herdecke (Germany)

\section{Contact information of authors:}

d-orlinsky@uchicago.edu

m.h.ronnestad@psykologi.uio.no

armin.hartmann@,uniklinik-freiburg.de

erkki.heinonen@,helsinki.fi

ulrike.willutzki@uni-wh.de

Correspondence may be addressed to: David Orlinsky, d-orlinsky@uchicago.edu, 5555 S.

Everett Avenue, Chicago, IL, 60637 


\title{
The Personal Self of Psychotherapists: Dimensions, Correlates and Relations with Clients
}

\author{
Abstract \\ Objective: The personal self of psychotherapists, i.e., experiences of self in close personal \\ relationships and its association with therapists' individual and professional attributes is \\ explored. The study aimed to: (a) describe therapists' self-ratings on specific self-attributes; (b) \\ determine their dimensionality; (c) explore demographic, psychological, and professional \\ correlates; and (d) assess the convergence with professional self. Method: Data from the \\ Development of Psychotherapists Common Core Questionnaire were available for $>10,000$
} psychotherapists of various professions, theoretical orientations, career levels, and nations. Results: Most psychotherapists described themselves in close relationships in affirming terms (e.g., warm/friendly), although a substantial minority also described themselves in negative terms. Factor analyses yielded four dimensions: Genial/Caring, Forceful/Exacting, Reclusive/Remote, and Ardent/Expressive. Being Genial/Caring was associated with life satisfaction. Among professional attributes, personal self-experiences and parallel dimensions of relationship with clients correlated strongly. Conclusions: Analyses of $>10,000$ psychotherapists revealed meaningful variations in personal self relevant to personal and professional life.

Keywords: psychotherapy; personality; social interaction; relationships; psychotherapists 


\section{Introduction}

When the personal self is brought in to psychotherapy, it is that of the patient which is normally center stage, while that of the therapist is kept aside. Nevertheless the therapist's personal self remains active though muted, and plays its part from the wings - coaching, prompting, responding humanely and empathically, but regrettably also sometimes distracting, obscuring or interfering with the therapist's work. While recognition of the difference between personal self and professional self is regarded as being part of the professional role of psychotherapists, areas of congruence between them are supposed to enable psychotherapists to "be spontaneous and alive in the work of psychotherapy" (Ecklar-Hart, 1987, p. 684; Kolden, Wang, Austin, Chang, \& Klein, 2018; Skovholt \& Rønnestad, 1995). The complex interplay between personal and professional aspects of self has stimulated researchers' interest in therapists' personal attributes (e.g., Ackerman \& Hilsenroth, 2003; Heinonen \& Nissen-Lie, 2019). In this, the interpersonal qualities and competencies of therapists play a prominent role as crucial for psychotherapy (e.g., Norcross \& Lambert, 2018; Orlinsky, Rønnestad \& Willutzki, 2004; Wampold \& Imel, 2015). The present paper empirically delineates the personal self of psychotherapists, examines some of its correlates, and assesses its degree of convergence with the therapist's professional self. The analyses draw on experiences of more than 10,000 therapists of different professions, theoretical orientations, and career levels from many countries - as reported via the Development of Psychotherapists Common Core Questionnaire (DPCCQ) (Orlinsky et al., 1999).

One section of the DPCCQ asks therapist to rate a series of items reflecting how they view themselves "in your close personal relationships." Personal self was defined as the set of self-representations that individuals form when engaging in close personal relationships, successively and cumulative as children, adolescents and adults. Typically these close 
relationships are intimate face-to-face bonds with immediate family members, close friends, mentors, partners and competitors, lovers and rivals. Over time, experiences in close relationships combine to shape the individual's personal self, and comprise the emotional core of personality. When core personal relationships are satisfying, life typically feels rich and meaningful; when they are full of conflict, suffering and loss, life can be miserable; and if personal relationships are scant or non-existent, life can feel empty and meaningless (e.g., Hawkley \& Cacioppo, 2010).

Additionally, people bring differing innate sensitivities and proclivities to their relationships, endowing them with individuality. This 'temperament'-factor (e.g., Shiner et al., 2012 ) is typically seen by parents of two or more, and may give strikingly different personalities to siblings raised in the same family environment. Variations in cognitive, affective, and enactive style tend to influence how persons engage in relationships, especially in the self-expressive relationships of personal life; and so also influence individuals' self-experience in these relationships. Thus, two important facets of the personal self of psychotherapists will be taken into account: relational manner and temperament, as expressed in close personal relationships.

\section{Prior Research}

Studies have examined therapists' personal traits in relation to therapeutic process and outcome (e.g., Orlinsky et al., 1996; Sandell et al., 2004); the role of personality in therapists' career development (e.g., Rønnestad \& Skovholt, 2003, 2013; Topolinski \& Hertel, 2007); and the match between therapists' theoretical orientations and personal characteristics (e.g., Arthur, 2001). Personal self and its relation to professional self also received much attention in the study of therapists' career development. A major finding of Rønnestad and Skovholt's longitudinal research was that positive professional development across career cohorts seems to involve a 
progressive integration of therapists' personal and professional selves (Rønnestad \& Skovholt 2003, 2013). Reports by the most experienced therapists indicated that adult as well as early life experiences were viewed as significant influences on their professional lives and self-perceptions (Rønnestad \& Skovholt, 2001).

Relevant background for the present study was provided by two theoretical models that view personality as anchored in interpersonal relations. Attachment theory has received attention as a perspective on therapists as well as patients (e.g., Black, Hardy, Turpin \& Parry, 2005;

Dinger, Strack, Sachsse \& Schauenberg, 2009; Marmarosh et al., 2013; Rek et al., 2018; Schauenberg, Dinger \& Buchheim, 2006; Steel, Macdonald \& Schroder, 2018). Other models are based on variants of the interpersonal circumplex (Leary, 1957). One is Benjamin's (1974) "Structural Analysis of Social Behavior" (SASB), operationalized via the Intrex questionnaire (e.g., Fincke, Möller \& Taubner, 2015; Nissen-Lie, Havik, Høglend, Monsen \& Rønnestad, 2013; Nissen-Lie, 2017; Steel, Macdonald \& Schroder, 2018; Taubner, Zimmermann, Kächele, Möller \& Sell, 2013). This version of the circumplex projects orthogonal dimensions of affiliation and control on three 'surfaces': self-towards-others (transitive), others-towards-self (intransitive), and self-towards-self (reflexive, or 'introject'). However, the Intrex views social behavior as a trans-situational attribute, without differentiating between types of relationship and social context. Another circumplex-inspired model is Kiesler's (1983) Interpersonal Message Impact theory, also in recent use (e.g., Coyne et al., 2018).

The present study complements earlier SASB-based research (Nissen-Lie et al., 2013, 2017; Taubner et al., 2013) that focused on the reflexive facet of self, by focusing here on the transitive (self-towards-others) aspect of self in the specific context of the therapist's private life. It examines the therapists' personal self, its intersections with demographic and social 
characteristics, and with professional characteristics beyond previously studied theoretical orientations (Heinonen \& Orlinsky, 2013).

\section{Research Questions}

The following research questions are addressed:

1. What are psychotherapists' most and least common self-described qualities of self in close personal relationships (i.e., their personal self), and what are its principal dimensions?

2. What social or professional characteristics are associated with therapists' personal self?

3. How much does therapists' professional self (i.e., self as experienced in relating to patients) have in common with their personal self?

\section{Methods}

\section{Measures}

Personal self. The concept personal self was operationalized with a set of 28 adjective scales in one section of the Development of Psychotherapists Common Core Questionnaire

(DPCCQ) as answers to the question "How would you describe yourself [e.g., as you are in your close personal relationships]?" (Orlinsky et al., 1999; Orlinsky \& Rønnestad, 2005). Sixteen scales reflecting interpersonal style were derived from the standard circumplex model (Leary, 1957) whose area is defined by combinations of two orthogonal bipolar axes: Affiliation (affirm vs. reject) and 'Control' (lead vs. follow). Each octant of the circumplex was represented in the DPCCQ by two adjectives (see Orlinsky \& Rønnestad, 2005, p. 44). Additionally, 12 adjective scales were selected to delineate temperament aspects of personal self, reflecting intensification vs. restraint in three broad areas: (a) affective-expressive style (energetic, intense, demonstrative vs. quiet, private, subtle); (b) cognitive-enactive style (organized, determined, pragmatic vs. intuitive, skeptical); (c) event-expectancy style (optimistic vs. fatalistic). The DPCCQ measure 
of personal self thus included a total of 28 scales (rated from ' $0=$ Not at all' to ' $3=$ Very much').

Social characteristics. The DPCCQ also included information on therapists' age, sex, family relationship status, immigration status, minority status, and nationality.

Personal quality of life. Therapists' quality of life was assessed by two multi-item scales from the DPCCQ. A scale of Personal Life Satisfaction $(\alpha=.82)$ involved experiences of unreserved enjoyment; free self-expression; feeling supported and cared for; emotional intimacy and rapport; and overall life satisfaction. A scale of Personal Life Burdens $(\alpha=.70)$ involved experiences of conflict; obligation to and worry for close others; loss; and overall life stress.

Professional characteristics. Other sections of the DPCCQ described professional background, years in practice, and theoretical orientation. Multiple scales were rated to assess the latter following the question "How much is your current therapeutic approach guided by each of the following theoretical frameworks?' Using a 6-point scale for the degree of influence on current practice (' $0=$ Not at all' to ' $5=$ Very much'), six orientations were rated: Analytic/ psychodynamic; Behavioral; Cognitive; Humanistic; Systemic; and Other (the mean of ratings on Behavioral and Cognitive scales was used for 'Cognitive-Behavioral').

Professional self. The therapists' professional self(i.e., self as experienced while treating patients) was operationalized with 28 adjective scales in a separate DPCCQ section placed far from the personal self-scales, but rated on the same 4-point scales. The question "How would you describe yourself as a therapist—your actual style or manner with clients?" was followed by the 16 interpersonal adjective scales used to assess personal self, plus 5 more reflecting aspects of individual temperament that might be displayed in professional relations (determined, organized, pragmatic, intuitive, subtle), and 7 more deemed specific to therapy: engagement 
(committed, involved vs. neutral) and efficacy (effective, skillful vs. confused, unhelpful).

Orlinsky and Rønnestad (2005) reported initial analysis of the professional self scales.

\section{Participants}

Data for this study was drawn from the cumulative database of the International Study of the Development of Psychotherapists (Orlinsky \& Rønnestad, 2005; Orlinsky, Rønnestad \& Willutzki, 2010). The Social Sciences Division research ethics committee of the University of Chicago approved the study. Participating psychotherapists provided data anonymously. A total $\mathrm{N}=12,036$ therapists completed most or all sections of the DPCCQ between 1991 and 2016. Their main demographic and professional characteristics are summarized in Table 1.

[Table 1 about here]

Demographic characteristics. Data came from more than 30 countries, 10 of which are represented by more than 400 therapists, another 15 countries by more than 100 each, plus several more countries with fewer than 100 . Of these, $63 \%$ were women. Their mean age was 45 years ( $s d=11.5$; range: $21-90)$. Personally, $60 \%$ were married or remarried; $12 \%$ lived with a partner; $10 \%$ were separated or divorced; $71 \%$ were parents.

Professional characteristics. Nearly half (49\%) of the therapists identified as psychologists; $20 \%$ as psychiatrists or medically trained; $19 \%$ as counselors; $6 \%$ as social workers, and $6 \%$ just as 'psychotherapists' or 'analysts'. Career level ranged from novices of a few months to seniors practicing for 50 years $(M=12$ years, $s d=9)$. The leading theoretical orientation categories were Analytic/psychodynamic $(M=2.99, s d=1.7)$, Humanistic $(M=2.46$, $s d=1.8)$, and Cognitive $(M=2.37, s d=1.7)$; followed by Systemic $(M=1.98, s d=1.7)$ and Behavioral $(M=1.89, s d=1.6)$. The combined Cognitive-Behavioral was $M=2.13(s d=1.5)$.

\section{Data Analysis}


This paper relies on item statistics for descriptive scales and exploratory factor-analysis (Principal Components extraction, Varimax rotation) for dimension reduction, computed separately for interpersonal and temperament items. Scale reliability analysis (Cronbach's $\alpha$ ) was used to determine which factor dimensions were viable as multi-item scales. One-way ANOVAs were used (with Scheffé post-hoc tests) to explore the relation of personal self to categorical social and professional variables (e.g., sex and profession) and Pearson correlations were used with continuous variables (e.g., age and orientation scales).

\section{Results}

Research question 1 was: What are therapists' most and least common self-qualities in close personal relationships (i.e., their personal self), and what are the principal dimensions of therapists' personal self? The relative incidence and dimensions of personal self-descriptors are summarized in Table 2, first for interpersonal and then for temperament-based scales.

[Table 2 about here]

Probably like most people in relationships with family and friends, $85 \%$ to $95 \%$ of therapists reported experiencing themselves as friendly, warm, accepting, tolerant, and nurturant. These adjectives, along with protective and receptive, range from the octant just above the Affirming pole (affirming/leading) to the octant just below it (affirming/following). Exploratory factor analysis (EFA) revealed the presence of the circumplex in two interpersonal dimensions: Affiliation (ID-1, 19\% of variance), named Genial/Caring, and Control (ID2, 16.4\% of variance), named Forceful/Exacting (both with acceptable level of reliability: $\alpha=.71$ ). EFA also revealed a third dimension: (ID-3, 12\% of variance) named Reclusive/Remote, reflecting the circumplex octant defined by negative Affiliation (rejecting) and negative Control (following), 
loading three items (reserved, guarded, cold) that while not itself acceptable reliable did become sufficiently $(\alpha=.71)$ combined with three correlated temperament items (noted below).

The lower section of Table 2 shows the temperament scales. Most therapists experienced themselves in close personal relationships as highly intuitive (84\%), optimistic (84\%), and energetic (76\%), as well pragmatic (72\%) and determined (71\%). Conversely, $25 \%$ reported being highly skeptical — which, given the context of intimate relationships, is noteworthy. EFA indicated three temperament dimensions, but only the first (TD-1, 17.8\% of variance), named Ardent/Expressive (defined by intense, energetic, intuitive, demonstrative and determined) showed adequate reliability ( $\alpha=.64)$. The third factor (TD-3, 13.9\% of variance) was defined as being skeptical, private and subtle, which itself was not reliable but reached an acceptable $\alpha$ of .71 (noted above) with the correlated items of Reclusive/Remote (ID-3).

Table 3 summarizes the descriptive statistics and inter-correlations of the four reliably measured dimensions of personal self for the sample. Only 'Genial/Caring' achieved a median score higher than 2.0 (i.e., between 'much' or 'very much'), but many therapists also experienced themselves as Ardent/Expressive with a median score of 1.80. However, judging from the $S D$ s, some therapists experienced themselves as only 'somewhat' Genial/Caring and also only "somewhat" Ardent/Expressive (scoring in the range of 1.0 to 1.5).

[Table 3 about here]

Similarly, while most therapists were 'somewhat' Forceful/Exacting, the ratings for directive, demanding, authoritative and critical show that a significant minority experienced themselves as 'forceful' (see Table 3, \% High). Least common of all in close relationships was experiencing oneself as Reclusive/Remote but the ratings for private, subtle, reserved, guarded, and skeptical (Table 3,\% High) show that many did perceive themselves as Reclusive/Remote. 
The right half of Table 3 shows the inter-correlations of the four dimensions. Being Ardent/Expressive was positively and substantially correlated with Genial/Caring $(r=.34)$ and Forceful/Exacting $(r=.37)$, although Genial and Forceful were negatively correlated with each other $(r=-.15)$. Evidently an Ardent/Expressive manner can express both intense caring and insistent demand. There was also a significant negative association between being Genial/Caring and being Reclusive/Remote ( $r=-.18$ ). Curiously, a significant positive correlation was found between Reclusive/Remote and Forceful/Exacting ( $r=.27)$, suggesting that the 'bossy' quality of Forceful/Exacting may partly compensate for an underlying impulse of anxious withdrawal.

Research question 2 was: What social or professional characteristics are associated with therapists' personal self? Analyses of categorical social and professional characteristics are presented in Table 4 and of continuous independent variables in Table 5. Small effects were statistically significant because of the very large sample size. Accordingly, comments are limited to scale differences above .10 and correlations above $r=.10$.

[Tables 4 \& 5 about here]

Social attributes. Regarding native vs. foreign origin, Table 4 shows that immigrant therapists were slightly less Reclusive/Remote than the native born. Therapists who said they would be viewed as minority group members were a little more Genial/Caring and Ardent/Expressive than their mainstream counterparts. Women were also more Genial/Caring and Ardent/Expressive than men. Separated or divorced therapists scored highest on Genial/Caring and Ardent/Expressive and lowest on Forceful/Exacting. Single therapists were highest on Reclusive/Remote and lowest on Genial/Caring, and childless therapists (mostly single) were also slightly more Reclusive/Remote. 
The correlations in the upper level of Table 5 show age was modestly related to experiences of personal self. Older therapists were significantly more Genial/Caring and Ardent/Expressive; younger therapists were more Forceful/Exacting and Reclusive/Remote. The largest correlations were found in relation to therapists' quality of life: the higher their Personal Life Satisfactions, the more they experienced themselves as Genial/Caring $(r=.42)$, as Ardent/Expressive $(r=.31)$, and as not Reclusive/Remote $(r=-.23)$. The higher their Personal Life Burdens, the more they experienced themselves as Forceful/Exacting $(r=.16)$ and as Reclusive/Remote $(r=.14)$.

Professional attributes. The bottom level of Table 4 shows differences in personal self associated with therapist professions. Psychologists were highest and counselors lowest in being Forceful/Exacting in close relationships. Psychiatrists as a group were personally the least Genial/Caring and Ardent/Expressive, and the most Reclusive/Remote. By contrast, counselors as a group were the most Genial/Caring and Ardent/Expressive, and the least Forceful/Exacting. Social workers as a group matched counselors in being most Genial/Caring and Ardent/Expressive, and were also least Reclusive/Remote. The group of 'therapists' and 'analysts' with no other professional identity were among the most Ardent/Expressive.

Correlations in the lower level of Table 5 show overall very limited association of therapists' personal self with career level measured by years in practice (less than for age). The only correlates of personal self with theoretical approach that are worth noting are those for Genial/Caring, which were positive for all except 'analytic/psychodynamic'.

Research question 3 was: How much do therapists' professional self (i.e., self as experienced in relating to patients) have in common with their personal self? The top section of 
Table 6 shows correlations between dimensions of self-experience in close personal relationships and dimensions of self-experience in therapeutic relationships.

[Table 6 about here]

Most notable are the substantial correlations in the main diagonal between corresponding dimensions of personal self and professional self. Therapists who felt Genial/Caring in personal relationships typically were Affirming with patients $(r=.52)$. Being Forceful/Exacting in personal relations corresponded with being Directive towards patients $(r=.48)$. Those who felt Reclusive/Remote in personal relations saw themselves as Reserved with patients $(r=.52)$. who Ardent/Expressive therapists experienced themselves as Effective with patients $(r=.46)$.

Off the main diagonal, therapists who were Genial/Caring personally viewed themselves with their patients as more Effective $(r=.38)$ and less Reserved $(r=-.21)$; those who were Forceful/Exacting personally tended to be more Reserved with patients $(r=.20)$.

The bottom section of Table 6 replicates the on-diagonal correlations for the 10 nations with $N$ s of 400 or more, showing the same personal-professional convergence in countries as diverse as Denmark and China, Canada and South Korea.

\section{Discussion}

\section{Research Questions: Answers and Comments}

(1) Personal self: traits and dimensions. Not surprisingly, almost all therapists $(\geq 94 \%)$ experienced themselves as warm and friendly in close personal relationships, and most $(>80 \%)$ also as accepting, tolerant, nurturant, and receptive, as well as intuitive and optimistic. Most of these traits are in octants of the interpersonal circumplex bordering the positive Affiliative axis. Such very high ratings may well be socially normative and aspirational, in addition to reflecting therapists' psychological reality. But these are measures of traits not states, and as inconstant 
states surely there are times when therapists vary. Other trait views might be obtained from ratings by therapists' families and friends. Regarding the latter, however, the results of a recent meta-analysis by Kim, Di Domenico and Connelly (2019) asking whether "self-report responses may be distorted by self-protecting motives and response biases"-especially in regards to "whether people see themselves more positively than they are seen by others ... showed that selfreport means generally did not differ from informant-report means" (p.129). On average their findings lend credence to our therapists' self-reports. Reinforcing this is the fact that many therapists (25\%-33\%) described themselves in negative terms as being reserved, guarded and skeptical, even in close relationships; and still more (36\%-39\%) acknowledged being directive, demanding, authoritative and critical in private life. That so many were willing to describe themselves in unflattering terms implies a creditable level of self-reflection and candor.

Exploratory factor analyses yielded three interpersonal factors and three temperament factors, four of which could be reliably scored. Two interpersonal dimensions clearly reflected the major axes of the interpersonal circumplex. Clinical support for the three interpersonal dimensions derives from their resemblance to Horney's (1950) view of basic human motivations as moving towards, against, and away from others. The fourth 'temperament' dimension reflected differences in how Ardent/Expressive therapists are personally: those high experiencing themselves as 'intense', those low experiencing themselves as 'easy-going'.

(2) Personal self and therapist characteristics. One-way ANOVA and correlational analyses indicated which social and professional characteristics were related to variations in therapists' personal self. Age, sex, and parental status appeared to be minor correlates, as were therapists' professional identity, career level, and theoretical orientation. The findings on orientation are less clear-cut than those of Heinonen and Orlinsky (2013) who concluded that 
"identification with particular theoretical orientations corresponds to aspects of therapists' personalities." This likely is due in part to the fact that the present study used the DPCCQ orientation scales directly rather than as a basis for constructing distinct orientation categories as was done in the previous paper.

The main correlates of therapists' personal self were psychological. Being Genial/Caring and Ardent/Expressive, and not Reclusive/Remote, were significantly associated with therapists' Personal Life Satisfactions. Being Forceful/Exacting and Reclusive/Remote were significantly linked to therapists' Personal Life Burdens. Do therapists who are personally genial and expressive experience more life satisfactions or do satisfied therapists experience themselves as more genial and expressive? Are therapists more demanding and reclusive when feeling more heavily burdened in private life or do personally burdened therapists relate to others in demanding and reclusive ways? Our data do not show influence in one or another or possibly both directions. Interestingly, a study by Nissen-Lie and colleagues (2013) using the DPCCQ life quality measures found that therapists' personal life burdens affected patients' ratings of their working alliance, but therapists' life satisfactions affected only their own alliance ratings.

(3) Personal self and professional self. The association between therapists' personal self and professional self was studied by Heinonen and Orlinsky (2013) by creating an index of discrepancy between the personal and professional dimensions. The present study, focusing on convergences instead, supports the earlier conclusion. Strong correlations were found between parallel dimensions of therapists' experiences of personal self in private life and professional self in relating with patients. Being Genial/Caring personally shared $27 \%$ variance with being Affirming with patients; Forceful/Exacting personally shared 23\% variance with being Directive towards patients; Reclusive/Remote in private life shared 27\% variance with being Reserved 
towards patients; being Ardent/Expressive personally shared $21 \%$ variance with feeling Effective with patients. This indicates a significant intersection of the therapist's personal self and professional self, one that may help therapists feel 'genuine'. However, the convergence also leaves room for distinctions based on the different social roles and boundaries that therapists have at home and at work. Heinonen and Orlinsky (2013, p. 727) observed that therapists "... experienced themselves as more intensively nurturing and protective in their close personal relationships, but also as more authoritative, critical and demanding, and rather less accepting or tolerant than when with clients" ... reflecting "the not unsurprising fact that therapists are more self-centered and less altruistic in that intimate private sphere of life ... where people typically seek satisfaction for their emotional needs." Another reflection of this divergence was described by Bernhardt et al. (2018, p. 6) as a "... tension between perceiving oneself as a helper while dealing with one's own needs for attention and care." Some boundaries are wise to preserve, as noted one senior therapist: "I hope some psychologists are not themselves with clients, because their selves are not therapeutic. [For them] it would be more important to learn to set limits on their personalities than to express them" (Rønnestad \& Skovholt, 2013, p. 108).

\section{Strengths and Limitations}

The main strength of the current study is its grounding in probably the largest and most diverse collection of psychotherapists to date. How representative the data are as a statistical sample is moot, because there is no universally accepted definition of 'psychotherapist' and hence no defined population from which a representative sample can be drawn. The alternative used here was to collect and study a large heterogeneous collection of clinicians who are identified with different professions at varied stages of their careers, trained in and practicing different treatment approaches, who live and work in many different countries. The fact that meaningful 
findings "emerge in spite of the potentially obscuring effect of this background variation" (Heinonen \& Orlinsky, 2013, p. 728) reflects the robustness of the findings.

The main limitations of this study are its reliance on self-report data, cross-sectional design, and exploratory character. (1) Self-report that is descriptive rather than evaluative (e.g., age, sex, marital status) typically is accepted at face-value and not questioned as potentially biased. The problem with self-report data may not be as much with self-enhancement bias (cf. Kim et al., 2019, noted above) as that it represents only one of several observational perspectives (i.e., therapists, clients, and raters). Drawing on two or more perspectives provides a deeper view into a complex social reality, as for example in studies by Hartmann, Joos, Orlinsky and Zeeck (2014), Heinonen et al. (2013), and Nissen-Lie et al. (2013) that demonstrate how therapists' experience of their professional work involvement, personal stresses or interpersonal relationships may impact on the one person's, but not the other's experience of the alliance.

(2) A cross-sectional design precludes determining relations of influence between variables, such as how much therapists' personal life satisfactions and burdens may influence their personal self or are influenced by that. A longitudinal study could also answer questions about the relative stability of personal self over time.

(3) The discovery-oriented nature of this study is reflected in limitations of both design and data analysis. The DPCCQ is an instrument that surveys many aspects of therapist experience, limiting the number of items devoted to each topic. Clearly no dimensions can emerge in a factor analysis if no relevant items were included. Reliable multi-item scales can't be constructed if too few items defined a factor dimension. These and other limitations can be viewed as invitations to future research on this humanly interesting and clinically relevant topic of the psychotherapist's personal self. 
Acknowledgments. The authors gratefully acknowledge the contributions of all other SPR/CRN colleagues who contributed significantly to the extensive database from which this study draws. 


\section{References}

Ackerman, S. J., \& Hilsenroth, M. J. (2003). A review of therapist characteristics and techniques positively impacting the therapeutic alliance. Clinical Psychology Review, 23, 1-33.

Arthur, A. R. (2001). Personality, epistemology and psychotherapists' choice of theoretical model: a review and analysis. European Journal of Psychotherapy \& Counselling, 4, 45-64.

Benjamin, L. S. (1974). Structural analysis of social behavior. Psychological Review, 81, 392425.

Bernhardt, I. S., Nissen-Lie, H., Moltu, C., McLeod, J., \& Rabu, M. (2018). "It's both a strength and a drawback." How therapists' personal qualities are experienced in their professional work. Psychotherapy Research, DOI: 10.1080/10503307.2018.1490972

Black, S., Hardy, G., Turpin, G., \& Parry, G. (2005). Self-reported attachment styles and therapeutic orientation of therapists and their relationship with reported general alliance quality and problems in therapy. Psychology and Psychotherapy, 78, 363-377.

Coyne, A. E., Constantino, M. J., Gomez Penedo, J. M., Gnall, K. E., Ravitz, P., \& McBride, C. (2018). Relation of patient and therapist interpersonal impact messages to outcome in interpersonal therapy for depression. Journal of Psychotherapy Integration, 28, 475-488.

Dinger, U., Strack, M., Sachsse, T., \& Schauenberg, H. (2009). Therapists' attachment, patients' interpersonal problems and alliance development over time in inpatient psychotherapy. Psychotherapy: Theory, Research, Practice, Training, 46, 277-290.

Ecklar-Hart, A. H. (1987). True and false self in the development of the psychotherapist. Psychotherapy, 24, 683-692. 
Fincke, J. I., Möller, H., \& Taubner, S. (2015). Does interpersonal behavior of psychotherapy trainees differ in private and professional relationships? Frontiers in Psychology, 6. doi: 10.3389/fpsyg.2015.00765.,

Hartmann, A., Joos, A., Orlinsky, D. E., \& Zeeck, A. (2014). Accuracy of therapist perceptions of patients' alliance: Exploring the divergence. Psychotherapy Research, 25, 408-419.

Hawkley, L. C., \& Cacioppo, J. T. (2010). Loneliness matters: A theoretical and empirical review of consequences and mechanisms. Annals of behavioral medicine, 40, 218-227.

Heinonen, E., Lindfors, O., Härkänen, T., Virtala, E., Jääskeläinen, T., \& Knekt, P. (2014).

Formatted: Finnish Therapists' professional and personal characteristics as predictors of working alliance in short-term and long-term psychotherapies. Clinical Psychology \& Psychotherapy, 21, 475494.

Heinonen, E., \& Nissen-Lie, H. A. (2019). The professional and personal characteristics of effective psychotherapists: A systematic review. Psychotherapy Research. doi: 10.1080/10503307.2019.1620366.

Heinonen, E., \& Orlinsky, D. E. (2013). Psychotherapists' personal identities, theoretical orientations, and professional relationships: Elective affinity and role adjustment as modes of congruence. Psychotherapy Research, 23, 718-731.

Horney, K. (1950). Neurosis and human growth. New York: Norton.

Kiesler, D. J. (1983). The 1982 Interpersonal Circle: A taxonomy for complementarity in human transactions. Psychological Review, 90, 185-214.

Kim, H., Di Domenico, S. I., \& Connelly, B. S. (2019). Self-other agreement in personality reports: A meta-analytic comparison of self- and informant-report means. Psychological Science. 30, 129-138. 
Kolden, G., Wang, C. C., Austin, S., Chang, Y., \& Klein, M. (2018).

Congruence/Genuineness. Psychotherapy, 55, 424-433.

Leary, T. (1957). Interpersonal diagnosis of behavior. New York: Ronald Press.

Marmarosh, C. L., Kivlighan, D. M., Bieri, K., LaFauci Schutt, J. M., Barone, C., \& Choi, J. (2014). The insecure psychotherapy base: Using client and therapist attachment styles to understand the early alliance. Psychotherapy, 5, 404-412.

Nissen-Lie, H. A., Havik, O. E., Høglend, P. A., Monsen, J. T., \& Rønnestad, M. H. (2013). The contribution of the quality of therapists' personal lives to the development of the working alliance. Journal of Counseling Psychology, 60, 483-495.

Nissen-Lie, H. A., Rønnestad, M. H., Høglend, P.A., Havik, O. E., Solbakken, O. A., Stiles, T. C., \& Monsen, J. T. (2017). Love yourself as a person, doubt yourself as a therapist? Clinical Psychology and Psychotherapy, 24, 48-60.

Norcross, J. C., \& Lambert, M. J. (2018). Psychotherapy relationships that work III. Psychotherapy, 55, 303-315.

Orlinsky, D. E., Ambühl, H., Rønnestad, M. H., Davis, J. D., Gerin, P., Davis, M., Willutzki, U., et al. (1999). The development of psychotherapists: Concepts, questions, and methods of a collaborative international study. Psychotherapy Research, 9, 127-153.

Orlinsky, D. E., \& Rønnestad, M. H. (2005). How psychotherapists develop: A study of therapeutic work and professional growth. Washington, DC: American Psychological Association.

Orlinsky, D. E., Rønnestad, M. H., \& Willutzki, U. (2004). Fifty years of process-outcome research: Continuity and change. In M. J. Lambert (Ed.), Bergin and Garfield's Handbook of psychotherapy and behavior change (5 ${ }^{\text {th }}$ ed.) (pp. 307-389). New York: Wiley. 
Orlinsky, D. E., Rønnestad, M. H., \& Willutzki, U. (2010). The SPR collaborative research program on the development of psychotherapists. In J. Norcross (Ed.), History of psychology: A century of change ( $2^{\text {nd }}$ ed.) (pp. 375-381). Washington, DC: American Psychological Association.

Orlinsky, D. E., Willutzki, U., Meyerberg, J., Cierpka, M., Buchheim, P., \& Ambühl, H. (1996) Die Qualität der therapeutischen Beziehung: Entsprechen gemeinsame Faktoren in der Psychotherapie gemeinsamen Characteristika von Psychotherapeutinnen? [Qualities of the psychotherapeutic relationship: Do common factors in psychotherapy reflect common characteristics of psychotherapists?] Psychotherapie, Psychosomatik, medizinische Psychologie, 46, 102-110.

Rek, I., Ehrenthal, J. C., Strauss, B. M., Schauenberg, H., Nikendei, C., \& Dinger, U. (2018). Attachment styles and interpersonal motives of psychotherapy trainees. Psychotherapy, 55, $209-215$.

Rønnestad, M. H., \& Skovholt, T. M. (2001). Learning arenas for professional development: Retrospective accounts of senior psychotherapists. Professional Psychology: Research and Practice, 32, 181-187.

Rønnestad, M. H., \& Skovholt, T. M. (2003). The journey of the counselor and therapist: Research findings and perspectives on professional development. Journal of Career Development, 30, 5-44.

Rønnestad, M. H., \& Skovholt, T. M. (2013). The developing practitioner: Growth and stagnation of therapists and counselors. New York \& London: Routledge. 
Sandell, R., Carlsson, J., Schubert, J., Broberg, J., Lazar, A., \& Grant, J. (2004). Therapist attitudes and patient outcomes: I. development and validation of the therapeutic attitudes scale (TASC-2). Psychotherapy Research, 14, 469-484.

Schauenberg, H., Dinger, U., \& Buchheim, A. (2006). Bindungsmuster von Psychotherapeuten [Attachment patterns in psychotherapists]. Zeitschrift für Psychosomatische Medizin und Psychotherapie, 52, 358-372.

Shiner, R. L., Buss, K. A., McClowry, S. G. Putnam, S. P., Saudino, K. J., \& Zentner, M. (2012). What is temperament now? Assessing progress in temperament research on the twenty-fifth anniversary of Goldsmith et al. Child Development Perspectives, 6, 436-444.

Skovholt, T. M., \& Rønnestad, M. H. (1995). The evolving professional self: Stages and themes in therapist and counselor development. Chichester: Wiley.

Steel, C., Macdonald, J., \& Schroder, T. (2018). A systematic review of the effect of therapists' internalized models of relationships on the quality of the therapeutic relationship. Journal of Clinical Psychology, 74, 5-42.

Taubner, S., Zimmermann, J., Kächele, H., Möller, H., \& Sell, C. (2013). The relationship of introject affiliation and personal therapy to trainee self-efficacy: A longitudinal study among psychotherapy trainees. Psychotherapy, 50, 167-177.

Topolinski, S., \& Hertel, G. (2007). The role of personality in psychotherapists' careers: Relationships between personality traits, therapeutic schools, and job satisfaction. Psychotherapy Research, 17, 378-390.

Wampold, B. E. \& Imel, Z. E. (2015). The great psychotherapy debate: The evidence for what makes psychotherapy work ( $2^{\text {nd }}$ ed.). New York: Routledge. 
Table 1

Psychotherapist Sample: Professional and Demographic Characteristics

\begin{tabular}{|c|c|c|}
\hline Profession & $N$ & $\%$ \\
\hline Psychology & 5611 & 49.1 \\
\hline Medicine/psychiatry & 2235 & 19.6 \\
\hline Counseling & 2193 & 19.2 \\
\hline Social work & 722 & 6.3 \\
\hline Psychotherapist & 661 & 5.8 \\
\hline Total & 11422 & $(94.9)$ \\
\hline Missing & 614 & \\
\hline \multirow[t]{2}{*}{ Years in Practice } & $M$ & $S D$ \\
\hline & 12.0 & 9.2 \\
\hline Range $=$ & \multicolumn{2}{|c|}{0.8 to 54.0} \\
\hline Theoretical Orientation & $M$ & $S D$ \\
\hline Analytic/psychodynamic & 2.99 & 1.74 \\
\hline Behavioral & 1.89 & 1.59 \\
\hline Cognitive & 2.37 & 1.67 \\
\hline$\left(_{\text {Cognitive-Behavioral })^{\mathrm{a}}}\right.$ & 2.13 & 1.51 \\
\hline Humanistic & 2.46 & 1.78 \\
\hline Systemic & 1.98 & 1.72 \\
\hline Nation $^{b}$ & $N$ & $\%$ \\
\hline Norway & 1678 & 16.6 \\
\hline USA & 1207 & 11.9 \\
\hline Germany & 1175 & 11.6 \\
\hline UK & 1108 & 10.9 \\
\hline Australia & 1004 & 9.9 \\
\hline Canada & 600 & 5.9 \\
\hline Denmark & 540 & 5.3 \\
\hline S Korea & 539 & 5.3 \\
\hline China & 509 & 5.0 \\
\hline Portugal & 416 & 4.1 \\
\hline $\operatorname{Sex}$ & $\mathrm{n}$ & $\%$ \\
\hline Women & 7533 & 63.3 \\
\hline Men & 4363 & 36.7 \\
\hline
\end{tabular}




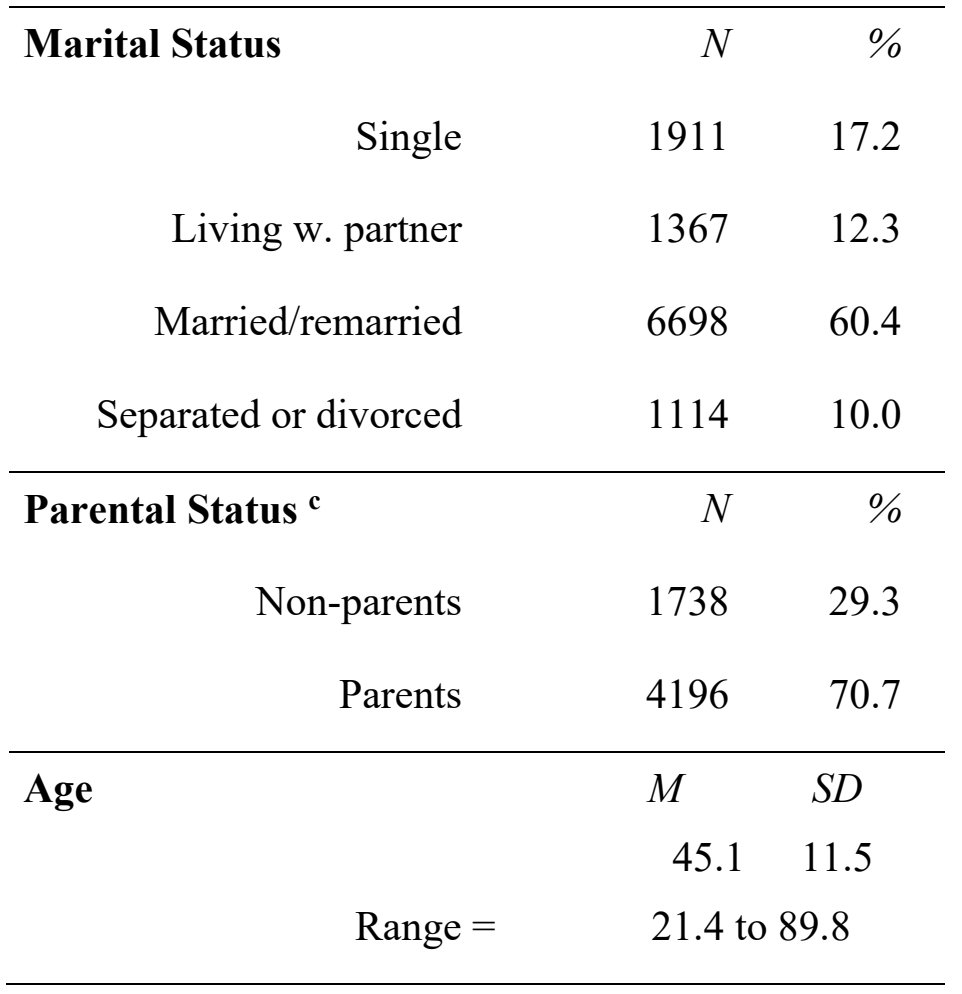

Note. ${ }^{\text {a }}-$ Cognitive-Behavioral $=($ Cognitive + Behavioral $/ 2)$.

$\mathrm{b}$ - Additional countries represented include New Zealand $(\mathrm{n}=331)$, Switzerland $(\mathrm{n}=306)$, India $(\mathrm{n}=$ 277), Austria $(n=234)$, Israel $(n=205)$, plus the following each with $n>100$ (Belgium, Chile, France, Greece, Ireland, Malaysia, Mexico, Russia, Spain, Sweden) accounting for a further $n=1362$ therapists. $c$ - Based on $50 \%$ sample $(n=5934)$ similar to total in marital status that received this question. 
Table 2

Personal Self Descriptors: Frequencies and Dimensions

\begin{tabular}{|c|c|c|c|c|c|c|c|}
\hline \multirow{2}{*}{$\begin{array}{l}\text { Interpersonal } \\
\text { Item Scales }\end{array}$} & \multirow{2}{*}{$\begin{array}{l}\text { Interpersonal } \\
\text { Octant }\end{array}$} & $M^{\mathrm{a}}$ & $S D$ & $\%$ High $^{b}$ & \multicolumn{3}{|c|}{ Dimensions $^{c}$} \\
\hline & & \multicolumn{3}{|c|}{$(\mathrm{n}=11,041)$} & ID-1 & ID-2 & ID-3 \\
\hline Warm & affirm & 2.46 & .63 & 94.0 & .71 & .04 & -.19 \\
\hline Friendly & affirm & 2.46 & .61 & 94.8 & .67 & .01 & -.18 \\
\hline Nurturant & affirm-lead & 2.25 & .75 & 85.2 & .67 & .12 & -.09 \\
\hline Tolerant & affirm-follow & 2.25 & .67 & 89.0 & .63 & -.18 & .07 \\
\hline Receptive & follow & 2.14 & .77 & 83.0 & .60 & -.08 & .00 \\
\hline Accepting & affirm-follow & 2.28 & .78 & 88.9 & .53 & -.25 & -.03 \\
\hline Protective & affirm-lead & 1.85 & .79 & 68.2 & .48 & .30 & .25 \\
\hline Permissive $^{\mathrm{e}}$ & follow & 1.41 & 1.04 & 52.8 & -- & -- & -- \\
\hline Directive & lead & 1.32 & .78 & 39.0 & .05 & .71 & -.02 \\
\hline Demanding & lead-reject & 1.26 & .86 & 37.5 & -.10 & .71 & .11 \\
\hline Authoritative & lead & 1.25 & .79 & 37.0 & -.00 & .67 & .02 \\
\hline Critical & reject & 1.27 & .83 & 36.4 & -.24 & .64 & .30 \\
\hline Challenging & lead-reject & 1.42 & .84 & 45.5 & .02 & .58 & -.04 \\
\hline Reserved & follow-reject & 1.17 & .81 & 31.7 & .02 & -.08 & .80 \\
\hline Guarded & follow-reject & 1.06 & .85 & 27.6 & -.02 & .10 & .76 \\
\hline \multirow[t]{3}{*}{ Cold } & reject & 0.39 & .63 & 6.2 & -.33 & .21 & .58 \\
\hline & & \multicolumn{3}{|r|}{$\%$ variance $=$} & 19.0 & 16.4 & 12.0 \\
\hline & & \multicolumn{3}{|c|}{ Standardized $\alpha=$} & .74 & .71 & $.60 / .71^{\mathrm{e}}$ \\
\hline \multirow{2}{*}{\multicolumn{2}{|c|}{$\begin{array}{l}\text { Temperament } \\
\text { Item Scales }\end{array}$}} & $M^{\mathrm{a}}$ & $S D$ & $\%$ High $^{\mathrm{b}}$ & \multicolumn{3}{|c|}{ Dimensions $^{c}$} \\
\hline & & \multicolumn{3}{|c|}{$(\mathrm{n}=10,806)$} & TD-1 & TD-2 & TD-3 \\
\hline Intense & & 1.69 & .88 & 59.1 & .64 & -.08 & .25 \\
\hline Energetic & & 2.04 & .78 & 76.2 & .60 & {$[.41]$} & -.19 \\
\hline Intuitive & & 2.24 & .77 & 83.6 & .57 & .05 & .16 \\
\hline Demonstrative & & 1.46 & .99 & 48.5 & .57 & .11 & -.02 \\
\hline Determined & & 1.92 & .79 & 71.3 & .54 & {$[.40]$} & .06 \\
\hline Quiet & & 1.51 & .87 & 49.7 & -.47 & .40 & .32 \\
\hline Organized & & 1.88 & .87 & 66.9 & .12 & .74 & -.06 \\
\hline Pragmatic & & 1.92 & .82 & 71.6 & .00 & .69 & .16 \\
\hline Optimistic & & 2.17 & .72 & 83.6 & .32 & .48 & -.31 \\
\hline Skeptical & & 1.03 & .79 & 24.8 & .01 & -.04 & .72 \\
\hline Private & & 1.49 & .91 & 47.3 & .01 & -.01 & .69 \\
\hline
\end{tabular}




\begin{tabular}{|c|c|c|c|c|c|}
\hline Subtle & 1.39 & 45.4 & .27 & .10 & .56 \\
\hline \multicolumn{3}{|c|}{$\%$ variance $=$} & 17.8 & 14.7 & 13.9 \\
\hline \multicolumn{3}{|c|}{ Standardized $\alpha=$} & .64 & .60 & $<.60 / .71^{\mathrm{e}}$ \\
\hline
\end{tabular}

Note. ${ }^{\text {a }}$ - Items rated on a 4-point scale $(0=$ Not at all; $1=$ Some; $2=$ Much; $3=$ Very much).

b - \% 'High' reflects a scale rating of 2 or 3.

${ }^{\mathrm{c}}$ - Bold print indicates used in factor score. ID-1 = Genial; ID-2 = Forceful; ID-3 = Reclusive; TD-1 = Ardent $;$ TD-2 = Businesslike; TD-3 = Remote .

d - Excluded from factor analysis due to missing data.

${ }^{\mathrm{e}}$ - Standardized $\alpha=.71$ if reserved, guarded \& cold combined with skeptical, subtle \& private. 
Table 3

Self in Close Personal Relationships: Dimension Statistics and Intercorrelations (Pearson's r)

\begin{tabular}{|c|c|c|c|c|c|c|c|c|c|}
\hline \multirow{2}{*}{ Dimension } & \multicolumn{5}{|c|}{ Scale Statistics } & \multicolumn{4}{|c|}{ Intercorrelations ${ }^{a}$} \\
\hline & $\mathrm{n}$ & $M^{\mathrm{b}}$ & Med & $S D$ & $\alpha$ & $\begin{array}{l}\text { Genial/ } \\
\text { Caring }\end{array}$ & $\begin{array}{l}\text { Forceful/ } \\
\text { Exacting }\end{array}$ & $\begin{array}{c}\text { Reclusive/ } \\
\text { Remote }\end{array}$ & $\begin{array}{c}\text { Ardent/ } \\
\text { Expressive }\end{array}$ \\
\hline Genial/Caring ${ }^{c}$ & 11,149 & 2.31 & 2.33 & .46 & .74 & --- & -.15 & -.18 & .34 \\
\hline Forceful/Exacting ${ }^{\mathrm{d}}$ & 11,136 & 1.30 & 1.20 & .56 & .71 & & --- & .27 & .37 \\
\hline Reclusive/Remote ${ }^{\mathrm{e}}$ & 11,108 & 1.10 & 1.17 & .52 & .71 & & & --- & .06 \\
\hline Ardent/Expressive ${ }^{f}$ & 11,143 & 1.87 & 1.80 & .54 & .64 & & & & --- \\
\hline
\end{tabular}

Note. ${ }^{\mathrm{a}}$ - $\mathrm{N}>11,000$ in all cells; all $p<.000$ due to large $\mathrm{n}$.

$\mathrm{b}$ - Scores reflect a 4-point scale $(0=$ Not at all; $1=$ Some; $2=$ Much; $3=$ Very much $)$.

c - Warm, friendly, nurturant, tolerant, receptive, accepting, protective.

d - Demanding, directive, authoritative, critical, challenging.

e - Reserved, guarded, cold, skeptical, subtle, private.

$\mathrm{f}$ - Intense, energetic, intuitive, demonstrative, determined. 
Table 4

Variations in Personal Self: Categorical Measures of Therapist Characteristics

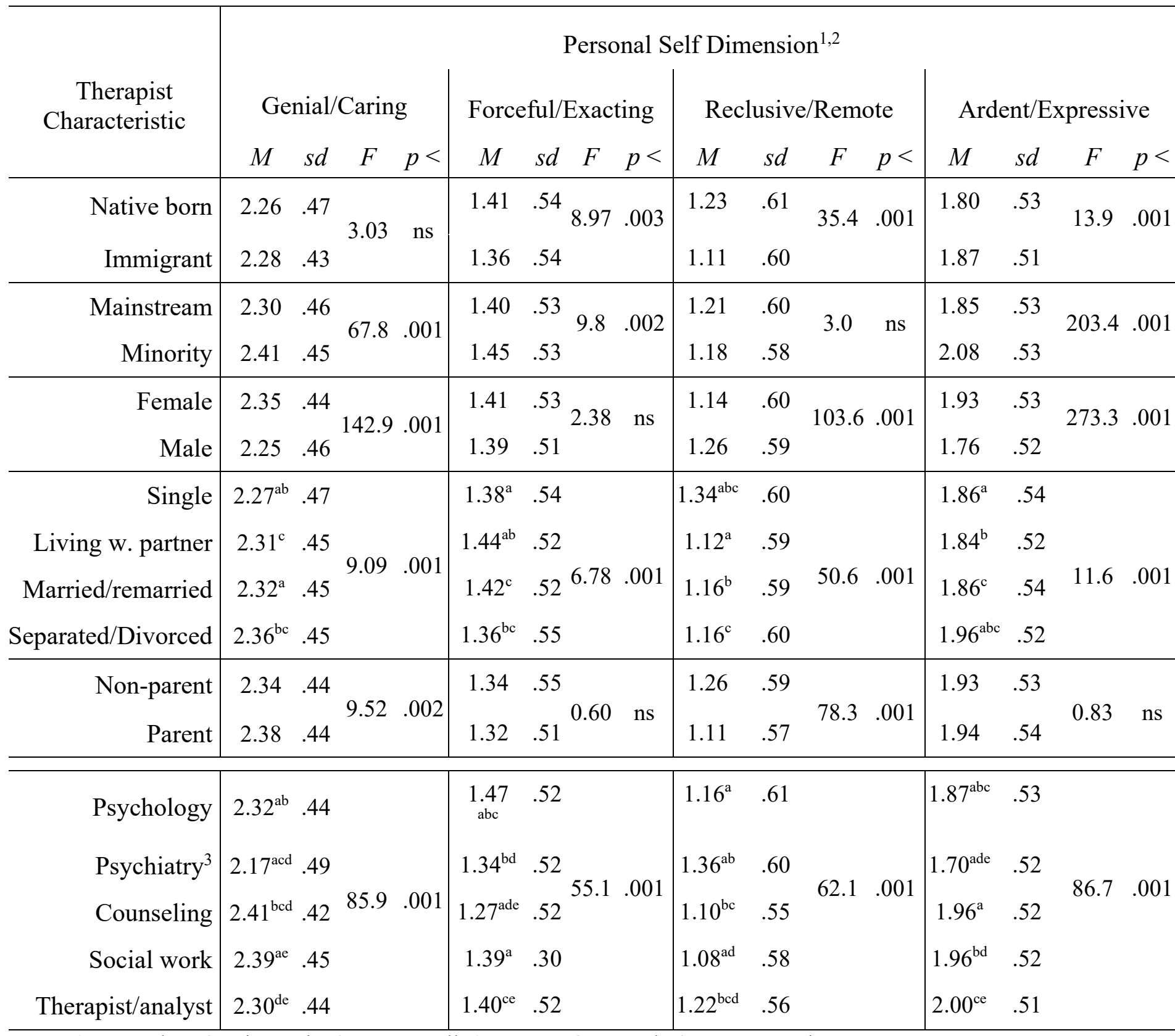

Note. 1 - Rated on 4-point scale: 0 = Not at all, 1 = Some, $2=$ Much, $3=$ Very much.

2 - Shared superscripts represent statistically significant subgroups based on post-hoc Scheffé analysis.

3 - Includes medically trained psychotherapists (in Germany). 
Table 5

Variations in Personal Self: Continuous Measures of Therapist Characteristics (Pearson's r)

\begin{tabular}{lcccc}
\hline & \multicolumn{4}{c}{ Personal Self Dimensions } \\
\cline { 2 - 5 } & $\begin{array}{c}\text { Genial/ } \\
\text { Caring }\end{array}$ & $\begin{array}{c}\text { Forceful/ } \\
\text { Exacting }\end{array}$ & $\begin{array}{c}\text { Reclusive/ } \\
\text { Remote }\end{array}$ & $\begin{array}{c}\text { Ardent/ } \\
\text { Expressive }\end{array}$ \\
\hline Age (years) & $.11^{* * * \mathrm{~b}}$ & $-.12^{* * *}$ & $-.12^{* * *}$ & $.04^{* * *}$ \\
Life Satisfactions & $.42^{* * *}$ & $.08^{* * *}$ & $-.23^{* * *}$ & $.31^{* * *}$ \\
Life Burdens & $-.08^{* * *}$ & $.16^{* * *}$ & $.14^{* * *}$ & $.09^{* * *}$ \\
$\quad$ & & & \\
Practice duration & $.07^{* * *}$ & $-.05^{* * *}$ & $-.07^{* * *}$ & $.05^{* * *}$ \\
Thears of therapy practice) & & & & \\
Analytic/psychodynamic & $-.04^{* * *}$ & $.03^{* * *}$ & $.04^{* * *}$ & -.01 \\
Behavioral & $.09^{* * *}$ & .01 & -.01 & .01 \\
Cognitive & $.13^{* * *}$ & -.01 & $-.09^{* * *}$ & -.01 \\
Cognitive-Behavioral a & $.12^{* * *}$ & -.01 & $-.08^{* * *}$ & -.00 \\
Humanistic & $.10^{* * *}$ & -.02 & -.01 & $.08^{* * *}$ \\
Systemic & $.12^{* * *}$ & $.04^{* * *}$ & $-.04^{* * *}$ & $.09^{* * *}$ \\
\hline
\end{tabular}

Note. ${ }^{\text {a }}$ "Cognitive-Behavioral" computed as scores for "Cognitive" + "Behavioral" divided by 2. $\mathrm{b}_{-} * * *-\mathrm{p}<.001$ 
Table 6

Correlations (Pearson's r) of Personal Self and Professional Self $(N \sim 10,868)$

\begin{tabular}{ccccc}
\hline \multirow{2}{*}{$\begin{array}{c}\text { Therapists' Self } \\
\text { in Relating with } \\
\text { Patients }\end{array}$} & \multicolumn{4}{c}{ Therapists' Self in Close Personal Relationships } \\
\cline { 2 - 5 } & $\begin{array}{c}\text { Genial/ } \\
\text { Caring }\end{array}$ & $\begin{array}{c}\text { Forceful/ } \\
\text { Exacting }\end{array}$ & $\begin{array}{c}\text { Reclusive/ } \\
\text { Remote }\end{array}$ & $\begin{array}{c}\text { Ardent/ } \\
\text { Expressive }\end{array}$ \\
\hline Affirming & $.52 * * * \mathrm{a}$ & $.04 * * *$ & $-.05 * * *$ & $.23 * * *$ \\
Directive & $-.03 * * *$ & $.48^{* * *}$ & $.23 * * *$ & $.19 * * *$ \\
Reserved & $-.21 * * *$ & $.20^{* * *}$ & $.52 * * *$ & -.00 \\
Effective & $.38^{* * *}$ & $.15^{* * *}$ & .02 & $.46^{* * *}$ \\
\hline
\end{tabular}

\begin{tabular}{crccc}
\hline Nation $^{\mathrm{b}}$ & $\mathrm{N} \sim$ & $\begin{array}{c}\text { Forceful } \mathrm{x} \\
\text { Directive }\end{array}$ & $\begin{array}{c}\text { Reclusive } \mathrm{x} \\
\text { Reserved }\end{array}$ & $\begin{array}{c}\text { Ardent } \mathrm{x} \\
\text { Effective }\end{array}$ \\
\hline Norway & 1610 & .44 & .46 & .33 \\
Germany & 1106 & .43 & .35 & .39 \\
UK & 1078 & .35 & .41 & .32 \\
USA & 975 & .43 & .47 & .31 \\
Australia & 950 & .43 & .36 & .34 \\
Denmark & 504 & .28 & .30 & .33 \\
S. Korea & 503 & .47 & .49 & .51 \\
China & 450 & .36 & .34 & .40 \\
Canada & 435 & .41 & .49 & .50 \\
Portugal & 374 & .47 & .42 & .42 \\
Others & 2811 & .48 & .47 & .41 \\
\hline
\end{tabular}

Note. ${ }^{\mathrm{a}}$ - *** $-\mathrm{p}<.001 ;{ }^{\mathrm{b}}$ Off-diagonal correlations of Genial (Personally) and Effective (Professionally) are consistently significant but always smaller than in-diagonal correlations between Genial and Affirming; In-diagonal correlations all significant $(\mathrm{p}<.001)$ 
